BOOK REVIEW

\section{Contraception: A Casebook from Menarche to Menopause}

Paula Briggs, Gabor Kovacs, John Guillebaud (eds). Cambridge, UK: Cambridge University Press, 2013. ISBN-13: 978-1-107-61466-6. Price: $£ 40.00 / U S \$ 62.00$. Pages: 256 (paperback)

You might think that with all the excellent guidance now so easily available there would be no need for a contraceptive textbook. However, this book, written and edited by leading world experts in contraception, is definitely a book to buy, read and refer to. Eminently readable, extremely comprehensive and authoritative, it is a book that provides a practical approach to contraception from menarche to the menopause. In addition, a holistic approach is taken by covering wider aspects of sexual and reproductive health care including abortion, infertility, sexually transmissible infections and sexual assault.

The book's introductory chapters place two things in context. First, an understanding of what women want from contraception - 'the need to listen', and how health professionals can support women to make confident good choices because when views and wishes are addressed, satisfaction and continuation of method use improves. Second, a helpful chapter covering the physiology of the menstrual cycle and natural family planning - not only does this provide a good basic understanding of women's reproduction and fertility, it enables improved understanding of how contraceptive methods work. It also illustrates why fertility awareness has a place in any discussion about preventing or planning pregnancy. All methods of contraception, including emergency contraception, are discussed (perhaps more on copper-containing intrauterine devices would have been useful other than their use as a postcoital method), providing guidance on prescribing, risks and advantages.

The different chapters usefully signpost readers to the relevant prescribing guidance by organisations such as the Faculty of Sexual \& Reproductive Healthcare (FSRH), the British Association of Sexual Health and HIV (BASHH) and the Royal College of Obstetricians and Gynaecologists (RCOG). Cancer and venous thromboembolism and other thrombotic risks of hormonal contraception - information that is often conflicting and contradictory, creating argument and debate - are well summarised, providing clear information both for health professionals and women.

There are good chapters looking at women's contraceptive needs at different ages, providing practical information and supported by useful case scenarios reflecting the diversity of problems and issues seen in daily practice. A clear message from these chapters is that age is not a barrier to most contraceptive methods (contrary to popular myth), and there is a need to choose methods that are not just medically eligible, but are ones that women want and are happy to use and that fit with their lifestyle needs.

This book should be essential reading for any health professional working in sexual and reproductive health, as well as those training and those needing to refresh their knowledge in this area.

Reviewed by Toni Belfield

Specialist in Sexual Health Information, Hampshire, UK; toni-b@tiscali.co.uk

J Fam Plann Reprod Health Care 2013;39:246. doi:10.1136/fprhc-2013-100755 